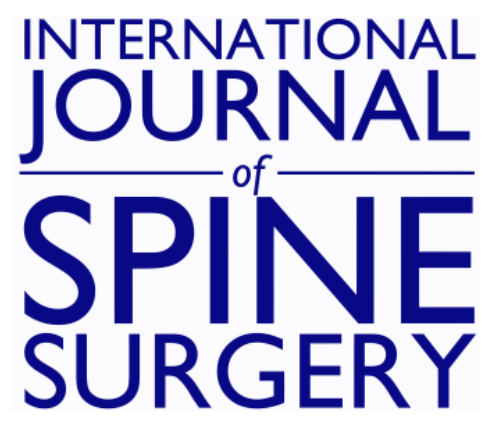

\title{
Mid-Term and Long-Term Clinical and Radiological Outcomes of a Carbon I/F Stand-Alone Cage in Anterior Lumbar Interbody Fusion
}

RJ KROEZE, SJ VERBERNE, HCA GRAAT, K SLOT, WJ PLUYMAKERS and OPP TEMMERMAN

Int J Spine Surg 2020, 14 (5) 665-670

doi: https://doi.org/10.14444/7097

http://ijssurgery.com/content/14/5/665

This information is current as of April 26, 2023.

Email Alerts Receive free email-alerts when new articles cite this article. Sign up at:

http://ijssurgery.com/alerts

The International Journal of Spine Surgery

2397 Waterbury Circle, Suite 1,

Aurora, IL 60504, Phone: +1-630-375-1432 


\title{
Mid-Term and Long-Term Clinical and Radiological Outcomes of a Carbon I/F Stand-Alone Cage in Anterior Lumbar Interbody Fusion
}

\author{
RJ KROEZE, MD, PhD, ${ }^{1}$ SJ VERBERNE, MD,${ }^{2 *}$ HCA GRAAT, MD, $\mathrm{PhD},{ }^{2} \mathrm{~K}$ SLOT, PA, ${ }^{2}$ WJ PLUYMAKERS, \\ $\mathrm{MD},{ }^{2}$ OPP TEMMERMAN, MD, $\mathrm{PhD}^{2}$ \\ ${ }^{I}$ Department of Orthopaedic Surgery, St. Maartenskliniek, Nijmegen, The Netherlands, ${ }^{2}$ Department of Orthopaedic Surgery, NWZ, Alkmaar, The Netherlands
}

\begin{abstract}
Study Design: Retrospective cohort study.

Objective: The current study was undertaken to determine the midterm and long-term radiological outcomes, complications and functional status of patients who underwent a single-level anterior interbody lumbar fusion (ALIF) procedure.

Summary of Background Data: Low back pain affects $70 \%-90 \%$ of the general population at some point in their life, and in general, the majority are best treated by nonsurgical therapy. However, a lumbar fusion can be considered in selected cases. In previous decades, lumbar interbody fusion procedures have gained popularity. Despite the approach used, stand-alone interbody fusion is becoming less popular due to poor fusion rates. When studying ALIF procedures, the addition of instrumentation results in higher fusion rates. Nevertheless, long-term follow-up can give either unexpected or similar insights into certain procedures that should be available in the current literature. Therefore, the current study was undertaken to determine the midterm and long-term radiological outcomes, complications, and functional status of patients who underwent a single-level ALIF procedure.

Methods: A cohort of 50 patients was studied following stand-alone ALIF for midterm and long-term follow-up of 6.6 years and 19.7 years, respectively. Primary outcome measurements were disability using the Oswestry Disability Index (ODI) score and pain scores using the visual analog scale, and the MOS 36-item Short-Form Health Survey (SF36) was used to evaluate the quality of life. In addition, radiographic assessment was performed to indicate the number of solid fusions.

Results: After a mean of 19.7 years, we had a loss to follow-up of $34 \%$. Functional measurements revealed an ODI of 41 for both time points and an SF-36 physical component score around 41.4 and 40.8 for the midterm and longterm follow-up, respectively. The mental component of the SF-36 was 48.7 and 49.9 , respectively. The assessment of interbody fusion revealed only $66 \%$ and $70 \%$ solid fusion after 6.6 years and 19.7 years, respectively.

Conclusions: In concordance with previous studies, the outcome of midterm and long-term results in this study showed that the I/F cage in ALIF procedures is a safe treatment option for single-level interbody fusion. The radiological results corroborate literature regarding stand-alone interbody fusion, and additional instrumentation is likely to increase fusion rates. However, functional measurements reveal that the postsurgical situation remains likely worse than patients in a healthy Dutch population but possibly better that in a back pain population.
\end{abstract}

Lumbar Spine

Keywords: ALIF, carbon I/F cage, fusion, midterm results

\section{INTRODUCTION}

Low back pain affects $70 \%-90 \%$ of the general population at some point in their lives, and in general, the majority are best treated by nonsurgical therapy. ${ }^{1,2}$ However, a lumbar fusion can be considered in case of persistent symptomatic degenerative disc disease, degenerative scoliosis, spondylolistheses, and/or spondylolysis. In previous decades, lumbar interbody fusion procedures have been popularized as an adjunct to increase fusion rates by adding intrinsic stability to the postoperative construct. In general, interbody fusion procedures can be through an anterior, a lateral, a transforaminal, or a posterior route. Various techniques have been described for such approaches with their own advantages and disadvantages. Despite the approach used, stand-alone interbody fusion is becoming less popular. 
In the case of an anterior lumbar interbody fusion (ALIF) procedure, the authors use additional instrumentation, such as an anterior plate or posterior translaminar or pedicle screws. However, when trying to pursue a long-term follow-up of a certain technique, new insights might have altered current practice. We believe that for stand-alone ALIF procedures, this might be the case since postoperative fusion and possible pseudarthrosis have been described as being more prevalent in ALIF with a stand-alone cage compared to ALIF with a cage and combined with pedicle instrumentation. ${ }^{3,4}$ Nevertheless, long-term follow-up can give either unexpected or similar insights into certain procedures that should be available in current literature.

Therefore, the current study was undertaken to determine the midterm and long-term radiological outcomes, complications, and functional status of patients who underwent a single-level ALIF procedure with use of a stand-alone carbon fiber Brantigan-I/F cage ${ }^{5,6}$ for lumbar degenerative disc degeneration and grade 1 degenerative spondylolisthesis performed by a single senior spine surgeon in 1 institution.

\section{MATERIALS AND METHODS}

\section{Study Design and Study Population}

After institutional approval by the medical ethics committee was obtained, all consecutive 73 patients who underwent an ALIF procedure with use of a stand-alone (Brantigan) I/F cage (Acromed, Cleveland, Ohio) filled with an iliac crest bone graft were approached to participate. All patients were operated on by a single surgeon in the period 1993-2002. All patients were treated conservatively for their low back pain for at least 6 months prior to the operation with physical therapy and anti-inflammatory medication. Patients were included in case of failed conservative treatment and a radiographically confirmed (plain radiography and MRI scan) singlelevel degenerative disc disease involving L3-L4, L4L5, or L5-S1 with or without mild degenerative spondylolisthesis (Myerding, grade 1). Exclusion criteria were multilevel disc disease, spondylolisthesis greater than grade 1, spondylolysis, or prior operative procedures on the spine. All patient files were retrospectively analyzed regarding length of stay, operative time, perioperative and postoperative complications, and revision rates. After this evaluation, all patients were seen in our outpatient clinic for follow-up measurements on 2 separate occasions-between December 2003 and October 2004 to collect midterm results and between November 2013 and February 2014-to collect long-term results. During each follow-up, their postoperative functioning levels (36-item ShortForm Health Survey [SF-36]), radiographs, and satisfaction with the surgical results were assessed. A patient's global assessment of treatment success was included, expressed as "good," "fair," or "poor." If patients were without any pain or disabilities, the score was excellent or good. If patients were able to do their normal work without pain or disability and suffered pain only during heavy tasks, they scored fair. If patients did not have any result of the operation and still suffered from daily pain and were not able to work or return to daily activities, they scored poor. Their "return to work" status was related and specified to their back pain and postoperative back status. Clinical examination included a standard neurological examination.

\section{Intervention}

All patients were operated through a left miniopen incision, retroperitoneal approach. After exposing the disc space, the anterior longitudinal ligament was excised, and the disc space was prepared for the cage while preserving the integrity of the bony end plates. The ALIF procedure was performed with a carbon $\mathrm{I} / \mathrm{F}$ cage filled with an iliac crest autograft within the cage. The procedures were performed by a single senior spine surgeon (AJG). Mobilization started on the first postoperative day. Patients were allowed to mobilize with a lumbosacral orthosis for the first 6 weeks after the surgery. Physical therapy was started during this period. Patients were instructed to avoid bending, lifting, and trunk rotation for the first 12 weeks.

\section{Primary Outcome Measures}

Disability was measured using the Oswestry Disability Index (ODI). ${ }^{7}$ A lower score indicates less disability, and a score below 22 is considered "normal." The visual analog scale (VAS) score $^{8}(0$ indicating no pain, 10 indicating the worst possible pain) was used for evaluation of pain. The SF-36 was used to evaluate the quality of life of patients, ${ }^{9}$ with higher scores representing a higher quality of life. The 36 questions were summarized into 2 
measures pertaining to physical health and mental health.

\section{Secondary Outcome Measures}

\section{Radiographic Assessment}

Plain radiographs in lateral, antero-posterior, and flexion-extension views of the lumbar spine were made at routine intervals (at 6 weeks, 3 months, 6 months, 1 year postoperation, and both study follow-up visits at 6.6 years [3.1-11.1 years] and 19.7 years [16-24 years]), respectively. The most recent radiographs were independently interpreted for intervertebral fusion by 2 experts ( 2 independent and nonaffiliated orthopedic surgeons) who were blinded to clinical pretest data and outcome. In case of disagreement, consensus was reached by discussion. Fusion was assessed using a 3-point radiographic score as described by van Dijk et $\mathrm{al}^{10}$ in 2002 and defined as bridging trabecular bone connecting the adjacent vertebral bodies through the implants (RS 2). In case of bone ingrowth with the cage securely fixed to the vertebral bone above and below but with a radiolucent discontinuity in the fusion mass, it was rated as RS 1 . If there was no ingrowth of bone within the cage, the fusion was rated as RS 0 and considered as pseudarthrosis.

\section{Additional Surgical Procedures}

Supplementary surgical procedures (eg, revisions or supplemental fixations) following primary surgery were regarded as a failed ALIF and these patients were excluded from further analysis.

\section{Adverse Events and Complications}

All complications up to 6 weeks after the surgical procedures were recorded and evaluated for their severity and relationship with the spinal implants and the ALIF procedures.

\section{Statistical Analysis}

Student $t$ tests were used for normally distributed continuous data, nonparametric tests for skewed continuous data, and Mann-Whitney tests for nominal data. Data were checked for normality and described as mean and standard deviation or as median and interquartile range. All statistical analysis was done with SPSS Statistics (IBM Corporation, Armonk, New York), version 20.

The intra- and interobserver agreement between the 2 observers was calculated using computer-
Table 1. Patient demographics.

\begin{tabular}{lcc}
\hline & Midterm & Long-Term \\
\hline Total patients & 50 & 33 \\
Female, n (\%) & $20(40)$ & $21(64)$ \\
Age at surgery, mean (range), y & $42(21-60)$ & $42.3(21-60)$ \\
Age at follow-up, mean (range), y & $49(31-67)$ & $62.5(44-80)$ \\
Working status, n (\%) & & \\
Not working & $16(32)$ & $11(33)$ \\
Working full-time & $28(56)$ & $19(58)$ \\
Working part-time & $6(12)$ & $3(9)$ \\
Non smoking/smoking, n (\%) & $38(76) / 12(24)$ & $26(79) / 7(21)$ \\
RS 0, nonsmoking/smoking & $0(0) / 2(17)$ & $0(0) / 1(14)$ \\
RS 1, nonsmoking/smoking & $12(32) / 3(25)$ & $8(31) / 1(14)$ \\
RS 2, nonsmoking/smoking & $26(68) / 7(58)$ & $18(69) / 5(72)$ \\
Level of surgery, n (\%) & & \\
L2-L3 & $2(4)$ & $1(3)$ \\
L3-L4 & $0(0)$ & $0(0)$ \\
L4-L5 & $10(20)$ & $6(18)$ \\
L5-S1 & $38(76)$ & $26(79)$ \\
\hline
\end{tabular}

${ }^{\mathrm{a}}$ Mean, $6.6 \mathrm{y}$; range, 3.1-11.1 y.

${ }^{\mathrm{b}}$ Mean, $19.7 \mathrm{y}$; range 16-24 y.

calculated kappa statistics (Microsoft Office Excel 2007, Microsoft, Redmond, Washington; http:// www.statstodo.com): Cohen's kappa ( $\kappa)$ for intraobserver reliability and Fleiss kappa for interobserver reliability. The Landis and Koch interpretation of kappa values $(\kappa>0.8$ equals almost perfect correlation, $\kappa=0.6-0.8$ as substantial agreement, $\kappa=0.4-0.6$ as moderate agreement, $\kappa=$ $0.2-0.4$ as fair agreement, and $\kappa<0.2$ as slight correlation) were used. Evaluation of statistical differences between kappa values was calculated with a $95 \%$ confidence interval, and differences were considered significant when the upper and lower boundaries did not overlap.

\section{RESULTS}

\section{Patient Follow-Up}

Table 1 shows the patient demographics. Of the 73 eligible patients, 58 patients agreed and were included and subsequently approached for analysis. Of these 58 patients, 50 were available for clinical midterm follow-up in our outpatient clinic. The 8 patients who were excluded either declined participation in this study $(\mathrm{N}=4)$ or had supplementary pedicle instrumentation $(\mathrm{N}=4)$. The carbon $\mathrm{I} / \mathrm{F}$ cage was implanted at L5-S1 in 38 patients $(76 \%)$, L4-L5 in 10 patients ( $20 \%$ ), and L3-L4 in 2 patients $(4 \%)$. In all patients, autologous bone was used from the iliac crest to impact the carbon fiber $\mathrm{I} / \mathrm{F}$ cages. Of the 50 patients of whom midterm results were collected, 33 returned for long-term follow-up measurements. 
Table 2a. Functional and pain scores.

\begin{tabular}{lcc}
\hline & Midterm $^{\mathbf{a}}(\mathbf{n}=\mathbf{5 0})$ & Long-Term $^{\mathbf{b}}(\mathbf{n}=\mathbf{3 3})$ \\
\hline ODI, mean \pm SD, 0-100 & $40.7 \pm 17.7$ & $40.7 \pm 13.5$ \\
SF-36, mean \pm SD, 0-100 & & \\
Physical component & $41.4 \pm 11.6$ & $40.8 \pm 11.3$ \\
Mental component & $48.7 \pm 10.4$ & $49.9 \pm 10.2$ \\
VAS, mean \pm SD, 0-10 cm & $3.5 \pm 2.5$ & $2.8 \pm 2.2$ \\
\hline
\end{tabular}

Abbreviations: ODI, Oswestry Disability Index; SF-36, 36-item Short-Form Health Survey; VAS, visual analog scale.

${ }^{a}$ Mean, $6.6 \mathrm{y}$; range, 3.1-11.1 y.

${ }^{\mathrm{b}}$ Mean, $19.7 \mathrm{y}$; range 16-24 y.

\section{Primary Outcome Measures}

All clinical results are presented in Table 2. No ODI, VAS, or SF-36 scores were available from before the surgery. At the first follow-up measurements, only 5 patients $(10 \%)$ had an ODI score of 22 or lower, indicating a normal level of disability. At the final follow-up visit, 2 patients (4\%) had a score below 22. The RS scores did not influenced the ODI, VAS, and SF-36 scores.

The 36 questions were summarized into 2 measures pertaining to physical health and mental health, as presented in Table 2a. Additionally, subscale scores were calculated and compared with results from the general Dutch population and lumbar spine patients ${ }^{11,12}$ (Table 2b).

\section{Secondary Outcome Measures}

\section{Radiographic Assessment}

Table 3 shows the assessment of interbody fusion, with only $66 \%$ and $70 \%$ solid fusion following midterm and long-term follow-up, respectively. The intraobserver reliability of the observers demonstrated moderate and substantial agreement $(\kappa=$ 0.56 and $\kappa=0.68$, respectively). Between the 2 observers, a substantial interobserver agreement $(\kappa$ $=0.63$ ) was found.

\section{Adverse Events and Complications}

Patients' admission charts were reviewed on adverse events that occurred during or within 6 weeks after surgery. No adverse events were recorded during surgery. One postoperative ileus (and therefore increased length hospital stay) was observed in the current patient group. Wound healing disturbances did not occur, and urinary retention requiring replacement of the temporary catheter occurred once. Neurologic deficits did not occur in the postoperative phase.
Table 2b. SF-36 results from this study compared with the Dutch reference population (Aaronson et $\mathrm{al}^{11}$ and a general spine surgical population Zanolli et $\left.\mathrm{al}^{12}\right)$.

\begin{tabular}{lcc}
\hline & $\begin{array}{c}\text { SF-36, } \\
\text { Physical } \\
\text { Component }\end{array}$ & $\begin{array}{c}\text { SF-36, } \\
\text { Mental } \\
\text { Component }\end{array}$ \\
\hline This study (midterm/long-term) & $41 / 41$ & $49 / 50$ \\
Aaronson et al $^{11}$ & 83 & 77 \\
Zanoli et al, DDD $^{12}$ & 30 & 57 \\
Zanoli et al, mean & & 62
\end{tabular}

Abbreviations: DDD, degenerative disc disease; SF-36, 36-item Short-Form Health Survey.

\section{DISCUSSION}

In this study of a cohort of 50 patients treated with a stand-alone carbon fiber $\mathrm{I} / \mathrm{F}$ cage in ALIF, the clinical outcome and radiographic fusion rates were retrospectively evaluated at a mean follow-up period of 6.6 years and 19.7 years, respectively. The results demonstrate that a stand-alone ALIF I/F cage provides satisfactory midterm and long-term clinical results compared to a previous study. ${ }^{13}$ In addition, when comparing our result to the study by Horsting et $\mathrm{al}^{14}$ (describing 10-year results of ALIF with additional posterior fixation), the results are comparable with respect to both functional outcome (SF-36) and pain (VAS). However, the same study describes an average ODI of 16.8 during 10-year follow-up, while our study describes an ODI of 41.8 at 6.6-year and 43.1 at 16.4-year follow-up.

\section{Primary Outcome Measures}

With regard to the primary outcome measures, no preoperative data sets were available for analysis, limiting the outcome measurements in this study. However, when comparing our postoperative data with the 1-year data available in the current literature, similar results were found. ${ }^{13,15}$ With regard to the SF-36 1-year data, however, we found a markedly higher score compared to the study by Li et al. ${ }^{13}$ We found no further studies or data with a similar long-term follow-up period that could be compared to the outcome of the present study. We therefore compared the results with the average SF-

Table 3. Radiographic scores (RS). ${ }^{a}$

\begin{tabular}{lcc}
\hline & Midterm $^{\mathbf{b}}(\mathbf{n}=\mathbf{5 0}), \mathbf{n}(\mathbf{\%})$ & Long-Term $^{\mathbf{c}}(\mathbf{n}=\mathbf{3 3}) \mathbf{n}(\mathbf{\%})$ \\
\hline RS 0 & $2(4)$ & $1(3)$ \\
RS 1 & $15(30)$ & $9(27)$ \\
RS 2 & $33(66)$ & $23(70)$ \\
\hline
\end{tabular}

${ }^{a}$ RS 0 = pseudarthrosis; RS 1 = bone ingrowth with radiolucent discontinuity; RS $2=$ bridging trabecular bone within cages

${ }^{\mathrm{b}}$ Mean, $6.6 \mathrm{y}$; range, 3.1-11.1 y.

${ }^{\mathrm{c}}$ Mean, $19.7 \mathrm{y}$; range 16-24 y. 
36 scores of the Dutch population and lower back pain patients. ${ }^{11,12}$ The current study showed that patients had better SF-36 scores after ALIF compared to patients but had not reached the levels of the average population.

\section{Secondary Outcome Measures}

The fusion rates found in the current study results are in line with radiographic fusion rates as reported by $\mathrm{Li}$ et al. ${ }^{13}$ The complexity of interpreting plain radiographs has long been recognized, which is likely to increase with more complex criteria, causing lower observer reliability. ${ }^{16}$ For this reason, the radiographic data were assessed using the criteria as defined by van Dijk et al, ${ }^{10}$ which provide a simple and validated set of criteria. ${ }^{16}$ The substantial agreement between the 2 observers in this study was comparable with previous described results $(\kappa=0.52) .^{22}$

Overall complication rates in the current study were low $(4 \%)$ and in concordance with the literature. ${ }^{13,15,17,18}$ One of the frequent complications of lumbar interbody fusion and stand-alone ALIF in particular is pseudarthrosis. Grubb and Lipscomb $^{3}$ reported a significant difference between a combined interbody fusion and pedicle instrumentation (circumferential) and interbody fusion alone. In a group of 101 patients, 53 were treated with interbody fusion and pedicle instrumentation, and 49 patients were treated with interbody fusion alone. Results showed that the instrumented group had a pseudarthrosis rate of $6 \%$, while the fusion stand-alone cage group experienced a pseudarthrosis rate of $35 \%$. Pseudarthrosis can occur due to biomechanical limitations in stabilization of the ALIF with a stand-alone cage. Lund et $\mathrm{al}^{4}$ reported that the cages decrease the intervertebral movement in flexion and lateral bending. However, spinal stabilization in extension and axial rotation was limited. Hence, some surgeons recommend that ALIF be supplemented by a posterior pedicle instrumentation despite the increased risk on adverse events. ${ }^{13,19}$ However, few results were published on this carbon fiber monosegmental stand-alone cage, in which Lübbers et $\mathrm{al}^{20}$ reported a series of 22 patients with excellent results and found similar results compared to Cho et al, ${ }^{21}$ who retrospectively reported an overall fusion rate of $88,3 \%$ with a mean follow-up of 21 months. No differences were found in the interbody fusion rate $(\mathrm{RS}=2)$ between smokers and nonsmokers $(72 \%$ versus $69 \%$, respectively). However, pseudarthrosis $(\mathrm{RS}=0)$ was found only in the smoking group $(\mathrm{n}=$ $1)$.

\section{Limitations}

The assessment of fusion in the current study was done using plain radiographs. Recent literature has shown that interbody fusion can probably be better evaluated using CT scans; ${ }^{22}$ however, for research purposes, it is difficult to obtain permission for CT scan of the patients due to the radiation dose. Therefore, x-rays are more appropriate. Furthermore, intraoperative testing is considered to be the gold standard, which, for obvious reasons, has not been performed in our patients. ${ }^{14,23,24}$ Another limitation is the number of patients who were lost to follow-up between the midterm and long-term measurements.

\section{CONCLUSIONS}

In concordance with previous studies, the outcome of midterm and long-term results in this study showed that the $\mathrm{I} / \mathrm{F}$ cage in ALIF procedures is a safe treatment option for single-level interbody fusion. The radiological results corroborate literature regarding stand-alone interbody fusion, and additional instrumentation is likely to increase fusion rates. However, functional measurements reveal that the postsurgical situation remains likely worse than patients in a healthy Dutch population but possibly better that in a back pain population.

\section{ACKNOWLEDGMENTS}

The authors honor the life accomplishments of Dr AJ de Gruijter. He was the senior spinal surgeon related to the present study and was considered an excellent scientific colleague and surgeon with a keen intellect and a friend by all who worked with him. He passed away on May 23, 2010, at the age of 54.

\section{REFERENCES}

1. Mannion AF, Brox JI, Fairbank JCT. Comparison of spinal fusion and nonoperative treatment in patients with chronic low back pain: long-term follow-up of three randomized controlled trials. Spine J. 2013;13(11):1438-1448

2. Zdeblick TA. The treatment of degenerative lumbar disorders. A critical review of the literature. Spine (Phila Pa). 1995;20(24 Suppl):126S-137S.

3. Grubb SA, Lipscomb HJ. Results of lumbosacral fusion 
for degenerative disc disease with and without instrumentation. Two- to five-year follow-up. Spine (Phila Pa). 1992;17(3):349355.

4. Lund T, Oxland TR, Jost B, Cripton P, Grassmann S, Etter C. Interbody cage stabilisation in the lumbar spine: biomechanical evaluation of cage design, posterior instrumentation and bone density. J Bone Jt Surg Br. 1998;80(2):351-359.

5. Brantigan JW, Steffee AD. A carbon fiber implant to aid interbody lumbar fusion. Two-year clinical results in the first 26 patients. Spine (Phila Pa). 1993;18(14):2106-2107.

6. Brantigan JW, Steffee AD, Lewis ML, Quinn LM, Persenaire JM, Brantigan I. Lumbar interbody fusion using the F cage for posterior lumbar interbody fusion and the variable pedicle screw placement system: two-year results from a Food and Drug Administration investigational device exemption clinical trial. (Spine Phila Pa). 2000;25(11):1437-1446

7. Fairbank JC, Couper J, Davies JB, O'Brien JP. The Oswestry low back pain disability questionnaire. Physiotherapy. 1980;66(8):271-273.

8. Zanoli G, Strömqvist B, Jönsson B. Visual analog scales for interpretation of back and leg pain intensity in patients operated for degenerative lumbar spine disorders. Spine (Phila Pa). 2001;26(21):2375-80.

9. McHorney CA, Ware JE Jr, Lu JF, Sherbourne CD. The MOS 36-item Short Form Health Survey (SF36): III. Tests of data quality scaling assumptions and reliability across diverse patient groups. Med Care. 1994; Jan;32(1):40-66.

10. van Dijk M, Smit TF, Burger EH, Wuisman PI. Bioabsorbable poly-L-lactic acid cages for lumbar interbody fusion: three-year follow-up radiographic, histologic, and histomorphometric analysis in goats. Spine. 2002;27(23):27062714

11. Aaronson NK, Muller M, Cohen PD, et al. Translation, validation, and norming of the Dutch language version of the SF-36 Health Survey in community and chronic disease populations. Epidemiology. 1998;51(11):1055-1068.

12. Zanoli G. Jönsson B, Strömqvist B. SF-36 scores in degenerative lumbar spine disorders analysis of prospective data from 451 patients. Acta Orthop. 2006;77(2):298-306.

13. Li J, Dumonski ML, Liu Q, et al. A multicenter study to evaluate the safety and efficacy of a stand-alone anterior carbon I/for anterior lumbar interbody fusion: two-year results from a Food and Drug Administration investigational device exemption clinical trial 1. Spine (Phila Pa). 2010;35(26):E1564E1570.

14. Horsting PP, Pavlov PW, Jacobs WCH, Obradov-Rajic M, de Kleuver M. Good functional outcome and adjacent segment disc quality 10 years after single-level anterior lumbar interbody fusion with posterior fixation. Glob Spine $J$. 2012;2(1):21-26.

15. Burkus JK, Gornet MF, Schuler TC, Kleeman TJ, Zdeblick TA. Six-year outcomes of anterior lumbar interbody arthrodesis with use of interbody fusion cages and recombinant human bone morphogenetic protein-2. J Bone Jt Surg Am. 2009;91(5):1181-1189.
16. Smit TH, Sugihara S, Burger EH, Wuisman PI. van DM, The effect of cage stiffness on the rate of lumbar interbody fusion: an in vivo model using poly(l-lactic acid) and titanium cages. Spine (Phila Pa). 2002;27(7):682-688.

17. DiPaola CP, Molinari RW. Posterior lumbar interbody fusion 1. J Am Acad Orthop Surg. 2008;16(3):130-139.

18. Scaduto AA, Gamradt SC, Yu WD, Huang J, Delamarter RB, Wang JC. Perioperative complications of threaded cylindrical lumbar interbody fusion devices: anterior versus posterior approach 1.J Spinal Disord Tech. 2003;16(6):502-507.

19. Gertzbein SD, Hollopeter MR, Hall S. Pseudarthrosis of the lumbar spine. Outcome after circumferential fusion. Spine (Phila Pa). 1998;23(21):2352-2356

20. Lubbers T, Bentlage C, Sandvoss G. Anterior lumbar interbody fusion as a treatment for chronic refractory lower back pain in disc degeneration and spondylolisthesis using carbon cages-stand alone. Zentralbl Neurochir. 2002;63(1):1217.

21. Cho JY, Jeong HT, Hyun YI, et al. Study of the fusion rate and clinical outcome after using paired stand-alone rectangular cages. Neurosurg Soc. 2004;36:28-33.

22. Kroeze RJ, Graat HC, Pluymakers WJ, et al. Interobserver and intraobserver reliability in the radiologic assessment of lumbar interbody fusion. Clin Spine Surg. 2016;30(6):E853E856.

23. Buchowski JM, Liu G, Bunmaprasert T, Rose PS, Riew KD. Anterior cervical fusion assessment: surgical exploration versus radiographic evaluation. Spine (Phila $\mathrm{Pa}$ ). 2008;33(11):1185-1191.

24. Song K-S, Chaiwat P, Kim HJ, Mesfin A, Park S-M, Riew KD. Anterior cervical fusion assessment using reconstructed computed tomographic scans: surgical confirmation of 254 segments. (Spine Phila Pa). 2013;38(25):2171-2177.

Disclosures and COI: None of the authors received payments or otherwise from a commercial entity. No commercial entity paid or directed any benefits to any organization with which the authors are affiliated or associated.

Corresponding Author: SJ Verberne, MD, Department of Orthopaedic Surgery, NWZ, Alkmaar, The Netherlands. Phone: 0725484444 Email: stevenverberne@hotmail.com.

Published 11 November 2020

This manuscript is generously published free of charge by ISASS, the International Society for the Advancement of Spine Surgery. Copyright (C) 2020 ISASS. To see more or order reprints or permissions, see http://ijssurgery.com. 